\title{
Comparison of ICSI Outcomes in Patients with Hydrosalpinx Pretreated with Either Laparoscopic Tubal Disconnection or Hysteroscopic Tubal Occlusion
}

Ismael Mohammed Elgarhy ${ }^{1}$, Ahmed Mohammed Rammah ${ }^{2}$, Mohammed Mohammed Saber Bakry ${ }^{3 *}$

Department of Obstetrics and Gynecology, ${ }^{1}$ Faculty of Medicine, Al-Azhar University, Cairo ${ }^{2}$ International Islamic

Center for Population Studies and Research, Al-Azhar University, Cairo ${ }^{3}$ Shebein Elkom Teaching Hospital

*Corresponding author: Mohammed Mohammed Saber Bakry, E-mail: mustafatolba@yahoo.com

\begin{abstract}
The aim of the study was to compare the efficacy of hysteroscopic tubal electrocoagulation versus laparoscopic tubal disconnection for management of hydrosalpinx related infertility among patients undergoing ICSI. The sample of the study was 100 patients. Half of the patients underwent hysteroscopic tubal electocoagulation who have laparoscopic contraindications, while the other half underwent laparoscopic tubal disconnection. After tubal occlusion was done, an ICSI cycle was startedwith assessment of chemical pregnancy rate. The rate of positive chemical pregnancy was $50 \%$ in hysteroscopic group and 58\% in laparoscopic group, so hysteroscopic tubal electrocoagulation was found to be a successful treatment for hydrosalpinges before ICSI when laparoscopy is contraindicated with chemical pregnancy rate comparable to laparoscopic tubal disconnection.
\end{abstract}

Keywords: Hydrosalpinx; Hysteroscopy; Infertility; Invitrofertilization; Laparoscopy.

\section{INTRODUCTION}

Tubal factor of infertility resulting from various forms of tuboperitoneal damage remains an extremely common cause of female infertility, accounting for more than $35 \%$ of all cases of female infertility. Probably the most severe form of tubal pathology is hydrosalpinx. Hydrosalpinx is a Greek word that means a Fallopian tube filled with water or fluid. Patients with hydrosalpinges have been identified as a subgroup with significantly lower implantation and pregnancy rates than patients with other tubal pathologies. An increased risk for early pregnancy loss and increased risk for ectopic pregnancies was reported, and many studies confirmed that the presence of hydrosalpinx significantly impairs IVF outcome as well ${ }^{(\mathbf{1})}$.

Patients with a hydrosalpinx have been found to have significantly poorer outcomes of IVF than do patients with tubal factor infertility but no hydrosalpinx (2). Hydrosalpinges in infertile women reduce the success of IVF by $50 \%{ }^{(3)}$. The harmful effect of a hydrosalpinx on pregnancy rates after IVF has been attributed to mechanical washout of the transferred embryos by tubal-uterine reflux of the hydrosalpinx fluid (4). Additionally, a hydrosalpinx might disturb endometrial receptivity: integrins, the best endometrial markers, show decreased expression in cases of hydrosalpinx ${ }^{(5)}$. Altered endometrial blood flow has also been proposed as a possible factor causing decreased rates of implantation ${ }^{(5)}$.

Any surgical interventions that disrupt tubaluterine communication in affected tubes might improve pregnancy rates ${ }^{(6)}$.

Laparoscopic salpingectomy was the most popular treatmentoption offered by the clinicians, followed by open salpingectomy, salpingostomy, proximal tubal occlusion and transvaginal ultrasonographic guided hydrosalpinx aspiration either beforeor during oocyte retrieval. The latest treatment option introduced was proximal occlusion of the hydrosalpinx by hysteroscopic placement of microinserts. Clinicians would still perform opensalpingectomy. The possible explanation for this could be thelack of training in endoscopic surgery and/or that patientswith tubal disease may have significant pelvic adhesions necessitating open surgery ${ }^{(7)}$.

Laparoscopic salpingectomy or tubal ligation has been shown to improve IVF outcomes for patients with a hydrosalpinx ${ }^{(8)}$.

However, this procedure has many drawbacks, including its invasiveness, the possibility of surgical injury (e.g. visceral injury, vascular damage, or unintended laparotomy), the potential risks from general anesthesia, and technical difficulty if there are pelvic adhesions. The proximal occlusion of a hydrosalpinx by hysteroscopy might offer a feasible therapeutic alternative when laparoscopy is technically difficult or contraindicated, with the advantage of hysteroscopic procedures of faster recovery, less hospitalization and rapid return to work, and in the future it might be done in the outpatient clinic as an office procedure ${ }^{(9)}$.

\section{AIM OF THE WORK}

The aim of the study was to compare the efficacy of hysteroscopic tubal electrocoagulation versus laparoscopic tubal disconnection for management of hydrosalpinx related infertility among patients undergoing ICSI. 
Comparison of ICSI Outcomes in Patients with Hydrosalpinx...

\section{PATIENTS AND METHODS}

A retrospective study was conducted on patients who had hydrosalpinges who were undergoing ICSI at ART unit at International Islamic Center for Population Studies and Research at Al-Azhar University and Al Hussein University hospital, between January 2016 and December 2017.

The Research Ethics Committee approved
the study protocol.
One hundred patients who have unilateral or
bilateral hydrosalpinges identified on hysterosalpingography and or vaginal ultrasonography, and were undergoing ICSI were enrolled in this study.

The patients were subdivided into 2 groups:

- Group 1: 50 patients underwent laparoscopic tubal disconnection.

- Group 2: 50 patients underwent hysteroscopic tubal electrocoagulation.

\section{Inclusion criteria}

1- Age between 18 and 41 years.

2- Primary or secondary infertility.

3- Diagnosis of hydrosalpinx; diagnosed by HSG and TV $\mathrm{U} / \mathrm{S}$.

4- Necessity of an ICSI procedure.

\section{Exclusion criteria}

1- Patients with uterine factor infertility such asfibroids (Type 0 or 1 ).

2- Patients with malefactorofinfertility.

3- Patients with tubal obstruction.

All eligible patients were submitted the following

1- History taking: Including duration and type of infertility (primary or secondary), sexual history, history suggestive of pelvic inflammatory disease, past history of pelvic surgery and history of chronic diseases.

2- Clinical examination: General and Local examination. Including weight, height, BMI, thyroid examination.Local bimanual examination (tenderness or masses) and speculum examination, done by infertility clinic specialist.

3- Laboratory investigations: All patients had an infertility work-up including; FSH, LH, estradiol serum level, prolactin and TSH, husband seminal analyses, routine labs in the form of: Complete blood count, $\mathrm{Rh}$ typing, urine analysis, random blood glucose level, liver and kidney functions and coagulation profile.

4- Pelvic sonography usinga 7.5 MHz vaginal probe of Samsung Medison X5 ultrasound machine. The uterus was scanned in the sagittal plane for detection of any endometrial abnormality; visible hydrosalpinx in the form of elongated, diluted, tortuous tube containing fluid which is anechoic was recorded. In ultrasound image, hydrosalpinx looks as a tubular shape, echogenic wall, folded configurations and linear echos in the lumen of the fallopian tube.

\section{5- Operation:}

1- Laparoscopic tubal disconnection: Laparoscopy wasdonefor half of the patients to confirm the presence of the hydrosalpinx, and unilateral or bilateral tubal disconnection was performed when technically feasible.

\section{Technique of Laparoscopic tubal disconnection}

Under general anesthesia, using $25 \mathrm{~mm}$ ports for entry at the right and left lower quadrants, the affected fallopian tube(s) was identified. The tube was grasped and the bipolar diathermy was applied $2-3 \mathrm{~cm}$ from the cornu followed by cutting of the diathermized point using scissors.

The contraindications for laparoscopy were mainly extensive abdominal or pelvic adhesions of various etiologies (e.g. previous surgery, pelvic inflammatory disease, and pelvic endometriosis) and morbid obesity. 2- Hysteroscopic tubal electrocoagulation: The other half of the patients who had contraindications for laparoscopy underwent hysteroscopic tubal electrocoagulation in the second week of their cycle.

\section{Technique of hysteroscopic tubal occlusion}

Hysteroscopic fulguration of internal orifice of fallopian tubes at a hysteroscopic unipolar coagulation power of $50 \mathrm{w}$ within duration of 20 s was used, which leads to degeneration of internal orifice tissue of diseased tube by electric heat energy to form tissue scar so as to prevent hydrosalpinx fluid reflux to uterine cavity, helping embryo's development and implantation.

\section{Induction of ovulation and embryo transfer at IVF} unit:

After tubal occlusion was done, an ICSI cycle was started as follows:

1. The induction protocol was the long luteal phase agonist protocol. Participants received gonadotrophin releasing hormone agonists ( $\mathrm{GnRHa}$ ) long protocol, Decapeptyl 0.1 $\mu \mathrm{g}$ SC injection daily starting on day 21 . After pituitary down regulation had been confirmed,by serum $\mathrm{E}_{2}<50 \mathrm{pg} / \mathrm{ml}, 225-300$ IU ofhuman menopausal gonadotropinsper day was started on day 3 of the cycle,then the dose was adjusted according to the response, being monitored by ultrasound on day 8 or 9 to establish the number of ovarian follicles.

2. Triggering of ovulation was done by 10000 units of human chorionic gonadotropin (hCG) IM when two or more follicles reach $18 \mathrm{~mm}$ in mean diameter.

3. Ovum retrieval using transvaginal ultrasound was scheduled 34-36 hours after hCG injection.

4. All grade embryos weretransferred on day 3-5 after ovum retrieval. 
5. Serum B-hCG test was done to confirm pregnancy two weeks after embryo transfer (chemical pregnancy).

The Primary outcome measure was pregnancy rate. We measured the following parameters to confirm the unity of distribution:

1. Number of oocytes collected in ICSI cycle.

2. Maturity of oocytes collected in ICSI cycle.

3. Number and quality of embryos transferred.

\section{Statistical methods}

Data were analyzed using Statistical Program for Social Science (SPSS) version 20.0. Quantitative data were expressed as mean \pm standard deviation (SD). Qualitative data were expressed as frequency and percentage.

Probability (p-value)

$p$-value $\leq 0.05$ was considered significant.

p-value $\leq 0.001$ was considered highly significant.

p-value $>0.05$ was considered insignificant.

\section{RESULTS}

The two groups were comparable regarding age, body mass index (BMI), type of infertility, duration of infertility, number of previous ICSI trials, and pretreatment hormonal profile as shown in table 1.

The outcome of ICSI cycles is shown in table 5. During oocyte retrieval, the total number of oocytes ranged from 1 to 18 with no significant difference between the two groups $(p=0.389)$. These ova were mainly in the mature metaphase I and II with no significant difference between the two groups in the number of MI oocytes $(\mathrm{p}=0.094)$ or MII oocytes ( $\mathrm{p}$ $0.084)$. There was no significant difference between the two groups in the total number of embryos $(\mathrm{p}=0.666)$ or grade A embryos $(\mathrm{p}=0.089)$. The proportions of pregnancies were comparable in the two groups $(\mathrm{p}=0.580)$. Twenty nine pregnancies were diagnosed chemically in laparoscopic disconnection group compared to twenty five in hysteroscopic group.

Table (1): Age, body mass index, type of infertility, duration of infertility and diagnosis of the two studied groups:

\begin{tabular}{|c|c|c|c|c|}
\hline Characteristics & $\begin{array}{l}\quad \text { Group 1 } \\
\text { Laparoscopic Tubal } \\
\text { Disconnection } \\
(\mathrm{N} 1=50)\end{array}$ & \begin{tabular}{l}
\multicolumn{1}{c}{ Group 2 } \\
Hysteroscopic Tubal \\
Electrocoagulation \\
$(\mathrm{N} 2=50)$
\end{tabular} & $\mathrm{P}$-value & $\begin{array}{l}\text { 95\%CLMEAN } \\
\text { DIFFERENCE }\end{array}$ \\
\hline Age(Years) & $31.54 \pm 4.63$ & $31.94 \pm 4.53$ & $0.66>0.05$ & $(-2.22: 1.41)$ \\
\hline $\mathrm{BMI}\left(\mathrm{kg} / \mathrm{m}^{2}\right)$ & $29.98 \pm 5.63$ & $29.99 \pm 4.98$ & $0.96>0.05$ & $(-2.11: 2.10)$ \\
\hline \multirow{2}{*}{$\begin{array}{cc}\text { Infertility: } & \begin{array}{c}\text { Primary } \\
\text { Secondary }\end{array}\end{array}$} & $36(72.00 \%)$ & $35(70.00 \%)$ & $0.83>0.05$ & \\
\hline & $14(28.00 \%)$ & $15(30.00 \%)$ & $0.83>0.05$ & \\
\hline $\begin{array}{l}\text { Duration of infertility } \\
\text { (year) }\end{array}$ & $5.30 \pm 2.62$ & $5.0 \pm 2.58$ & $0.59>0.05$ & $(-0.75: 1.31)$ \\
\hline $\begin{array}{l}\text { Primary diagnosis: } \\
\text { Unilateral Hx }\end{array}$ & $22(44.00 \%)$ & $32(64.00 \%)$ & $0.83>0.05$ & \\
\hline Bilateral Hx & $28(56.00 \%)$ & $18(36.00 \%)$ & $0.83>0.05$ & \\
\hline $\begin{array}{r}\text { Secondary diagnosis: } \\
\text { Anovulation }\end{array}$ & $14(28.00 \%)$ & $13(26.00 \%)$ & $>0.05$ & \\
\hline POR & $8(16.00 \%)$ & $10(20.00 \%)$ & $>0.05$ & \\
\hline Male factor & $19(38.00 \%)$ & $14(38.00 \%)$ & $>0.05$ & \\
\hline Unexplained & $9(18.00 \%)$ & $13(26.00 \%)$ & $>0.05$ & \\
\hline
\end{tabular}

Values are given as mean \pm SD or number (percentage).

Table 2: Hormonal profile of the two studied group.

\begin{tabular}{|c|l|l|l|c|}
\hline Group & Group1 & Group2 & P-VALUE & $\begin{array}{l}\text { 95\%CL MEAN } \\
\text { DIFFERENCE }\end{array}$ \\
\hline Hormones & $6.81 \pm 1.55$ & $7.14 \pm 1.60$ & $0.52>0.05$ & $(-1.35: 0.69)$ \\
\hline FSH(IU/ml) & $4.49 \pm 1.47$ & $4.41 \pm 1.96$ & $0.86>0.05$ & $(-0.81: 0.97)$ \\
\hline LH(IU/ml) & $16.88 \pm 2.64$ & $17.88 \pm 2.56$ & $0.56>0.05$ & $(-4.41: 2.41)$ \\
\hline Prolactin(ng/ml) & $55.82 \pm 5.47$ & $57.59 \pm 3.79$ & $0.72>0.05$ & $(-11.55: 8.01)$ \\
\hline Estradiol $(\mathrm{pg} / \mathrm{ml})$ & $2.85 \pm 0.88$ & $2.66 \pm 0.75$ & $0.60>0.05$ & $(-0.53: 0.91)$ \\
\hline AMH $(\mathrm{ng} / \mathrm{ml})$ & $2.58 \pm 0.13$ & $2.47 \pm 0.14$ & $0.63>0.05$ & $(-0.34: 0.56)$ \\
\hline TSH $(\mathrm{miu} / \mathrm{ml})$ &
\end{tabular}

Values are given as mean \pm SD. 
Table 3: Total number and phase of retrieved ova in the two studied group.

\begin{tabular}{|c|l|l|l|}
\hline Group & $\begin{array}{c}\text { Group1 } \\
\text { N1=50 }\end{array}$ & $\begin{array}{c}\text { Group2 } \\
\text { N2=50 }\end{array}$ & P-VALUE \\
\hline Votal No Ova Retrieved & $11.2 \pm 2.6$ & $12 \pm 2.6$ & $0.389(>0.05)$ \\
\hline No. of MII oocytes & $9.08 \pm 2.46$ & $10.45 \pm 2.6$ & $0.084(>0.05)$ \\
\hline No. of MI oocytes & $1 \pm 1.1$ & $0.5 \pm 0.6$ & $0.094(>0.05)$ \\
\hline No. of GV oocytes & $1.04 \pm 0.75$ & $0.8 \pm 0.894$ & $0.335(>0.05)$ \\
\hline No. of Atretic ova & $0.17 \pm 0.38$ & $0.2 \pm 0.5$ & $0.808(>0.05)$ \\
\hline
\end{tabular}

GV: germinal vesicle phase, MI: metaphase I, MII: metaphase II.

Data presented as median $\pm \mathrm{SD}$

Table 4: Total number and grade of produced embryos in the two studied group.

\begin{tabular}{|c|c|c|c|}
\hline Group & $\begin{array}{c}\text { Group I } \\
\text { N1=50 }\end{array}$ & $\begin{array}{c}\text { Group II } \\
\text { N2=50 }\end{array}$ & P-VALUE \\
\hline Total No. Of Embryos produced & $7(5-10))$ & $7(4-10)$ & $0.666(>0.05)$ \\
\hline Total No. Of Embryos transferred & $2 \pm 2.5(1-3)$ & $2 \pm 2.5(1-3)$ & $0.00(>0.05)$ \\
\hline Grade A & $2.00 \pm 2.00(0-3)$ & $2.00 \pm 1.50(0-3)$ & $0.0891(>0.05)$ \\
\hline Grade B & $0.00 \pm 0.5(1-2)$ & $0.00 \pm 0.5(1-2)$ & $0.00(>0.05)$ \\
\hline Grade C & $0(0-2)$ & $1(0-3)$ & $0.312(>0.05)$ \\
\hline
\end{tabular}

Data presented as median (range).

Table 5: Proportion of pregnancies in the two studied groups.

\begin{tabular}{|c|c|c|c|}
\hline \multicolumn{2}{|c|}{ Variable } & $\begin{array}{c}\text { Positive } \\
\text { (T1=54) }\end{array}$ & $\begin{array}{c}\text { Negative } \\
\text { (T2=46) }\end{array}$ \\
\hline \multicolumn{2}{|c|}{ Group 1(N1=50) } & $\mathbf{2 9}(\mathbf{5 8 . 0 0 \% )}$ & $\mathbf{2 1 ( 4 2 . 0 0 \% )}$ \\
\hline Group2(N2=50) & 25(50.00\%) & $\mathbf{2 5 ( 5 0 . 0 0 \% )}$ \\
\hline & Point & $\mathbf{9 5 \%}$ Confidence Interval & Point \\
\hline PARAMETERS: Risk-based & Estimate & Lower & Estimate \\
\hline Risk Ratio (RR) & 1.1600 & & 0.8061 \\
\hline
\end{tabular}

Values are given as number (percentage)

\section{DISCUSSION}

Hysteroscopic tubal electrocoagulation was found to be a successful treatment for hydrosalpinges before ICSI when laparoscopy is contraindicated with pregnancy rate comparable to laparoscopic tubal disconnection. The present retrospective clinical trial had investigated the success rate of hysteroscopic tubal electrocoagulation for the treatment of hydrosalpinxrelated infertility in patients with laparoscopic contraindications undergoing ICSI.

The pregnancy rate was $29(58 \%)$ of 50 cases in group 1 and 25(50\%) of 50 cases in group 2with no significant difference between the two groups.

Hysteroscopic tubal electrocoagulation might be a possible alternative for hydrosalpinx treatment before ICSI. However, hysteroscopic surgery is associated with both the potential risk of electrosurgical injury and complications of distending media. Electrosurgical injury can be avoided by proper insulation and by using the lowest possible power setting, whereas complications of distending media can be prevented by proper monitoring of fluid input and output, and by keeping the uterine cavity distention pressure below the mean arterial pressure to avoid fluid and electrolyte disturbances. Sufficient evidence shows the negative effect of hydrosalpinx fluid in the uterine cavity on female fecundity, in addition to the significant improvement in fertility after occlusion of the hydrosalpinx ${ }^{(10)}$. Although laparoscopic procedures (salpingectomy or proximal tubal disconnection) have proven efficacy, the cumulative risks for patients intending to undergo ICSI treatment are a concern. Hysteroscopic procedures (either an Essure insert or electrocoagulation) are regarded as simpler and safer ${ }^{(11)}$.

There was a pilot study to evaluate the first trial of hysteroscopic tubal electrocoagulation as a method for tubal occlusion in cases with hydrosalpinx. The hysteroscopic route as a method for tubal occlusion in 
cases with hydrosalpinx was only used as a case report by Rosenfield et al $^{(\mathbf{1 2})}$ in which he used the ESSURE set for tubal occlusion and it was a successful trial but this method is more expensive than the method we used.

A pilot study by Aboulghar et $\boldsymbol{a l} .{ }^{(\mathbf{1 3})}$ previously compared hysteroscopic roller ball and needle electrode coagulation of the cornual end of the tubes for occlusion of a communicating hydrosalpinx among 10 patients scheduled for IVF. In the roller ball group (6 tubes/4 patients), one tube was successfully closed, three tubes remained partially open, and two tubes were found to be completely open. The needle electrode group (10 tubes/6 patients) had a $90 \%$ success rate of occlusion (only one tube was found to be open). However, that study had a very limited number of cases.

A prospective clinical trial by El-Mazny et $\boldsymbol{a l l}^{\left({ }^{(\mathbf{9})}\right.}$ had investigated the success rate of hysteroscopic tubal electrocoagulation for the treatment of hydrosalpinxrelated infertility among a relatively large number of patients with laparoscopic contraindications undergoing IVF, Overall, the procedure was successful in terms of tubal occlusion for 25 (93\%) of 27 hydrosalpinges in hysteroscopic group and 78 (96\%) of 81 hydrosalpinges in laparoscopic group, with no significant difference between the two groups. These results are close to our study results and that may be due to some common points that were used in both studies, as all the hysteroscopic procedures in both studies were performed in the early follicular phase and the instruments used were close to each other, as they used in this previous study the electrocoagulation roller ball as we used in our study.

\section{CONCLUSION}

Surgical treatment of hydrosalpinx prior to ICSI cycles can be done through hysteroscopic occlusion of the cornual end of the affected tube or laparoscopic disconnection of the hydrosalpinx. The two techniques are generally safe with comparable efficacy and chemical pregnancy rate, so the proximal occlusion of a hydrosalpinx by hysteroscopy might offer a feasible therapeutic alternative when laparoscopy is technically difficult or contraindicated.

\section{REFERENCES}

1. Andersen AN, Yue $\mathrm{Z}$, Meng FJ et al. (1994): Implantation: Low implantation rate after in-vitro fertilization in patients with hydrosalpinges diagnosed by ultrasonography. Human Reproduction, 9(10):1935-8.

2. Ayida G, Kennedy S, Barlow D et al. (1996): A comparison of patient tolerance of hysterosalpingo- contrast sonography (HyCoSy) with Echovist ${ }^{\circledR}-200$ and $\mathrm{X}$-ray hysterosalpingography for outpatient investigation of infertile women. Ultrasound in Obstetrics \& Gynecology, 7(3):201-4.

3. Arora P, Arora RS, Cahill D (2014): Essure ${ }^{\circledR}$ for management of hydrosalpinx prior to in vitro fertilisation-a systematic review and pooled analysis. BJOG: An International Journal of Obstetrics \& Gynaecology, 121(5):527-36.

4. Barbosa MW, Sotiriadis A, Papatheodorou SI et al. (2016): High miscarriage rate in women treated with Essure ${ }^{\circledR}$ for hydrosalpinx before embryo transfer: a systematic review and meta-analysis. Ultrasound in Obstetrics \& Gynecology, 48(5):556-65.

5. Beyler SA, James KP, Fritz MA et al. (1997): Hydrosalpingeal fluid inhibits in-vitro embryonic development in a murine model. Human Reproduction (Oxford, England), 12(12):2724-8.

6. Parihar M, Mirge A, Hasabe R (2009): Hydrosalpinx functional surgery or salpingectomy? The importance of hydrosalpinx fluid in assisted reproductive technologies. Journal of Gynecological Endoscopy and Surgery, 1(1):12-18.

7. Hammadieh N, Afnan M, Evans J et al. (2004): A postal survey of hydrosalpinx management prior to IVF in the United Kingdom. Human Reproduction,19(4):1009-12.

8. Kontoravdis A, Makrakis E, Pantos K et al. (2006): Proximal tubal occlusion and salpingectomy result in similar improvement in in vitro fertilization outcome in patients with hydrosalpinx. Fertility and Sterility, 86(6):1642-9.

9. El-Mazny A, Abou-Salem N, Hammam M et al. (2015): Hysteroscopic tubal electrocoagulation versus laparoscopic tubal ligation for patients with hydrosalpinges undergoing in vitro fertilization. International Journal of Gynecology \& Obstetrics, 130(3):250-2.

10. Ozgur K, Bulut H, Berkkanoglu M et al. (2014): ICSI pregnancy outcomes following hysteroscopic placement of Essure devices for hydrosalpinx in laparoscopic contraindicated patients. Reproductive Biomedicine Online, 29(1):113-8.

11. Shah V, Panay N, Williamson $R$ et al. (2011): Hysterosalpingogram: an essential examination following Essure hysteroscopic sterilisation. The British Journal of Radiology, 84(1005):805-12.

12. Rosenfield RB, Stones RE, Coates A et al. (2005): Proximal occlusion of hydrosalpinx by hysteroscopic placement of microinsert before in vitro fertilizationembryo transfer. Fertility and Sterility,83(5):1547-e11.

13. Aboulghar MM, Azmy O, Nada A et al. (2008): Hysteroscopic tubal electrocoagulation in cases with communicating hydrosalpinx and planning for IVF-a pilot study. Int J Med., 1(2):81-5. 